\title{
Development of a reliable path-loss model for FM broadcast reception in office locations
}

\author{
Marco G. Domingo, Prince Kendrick E. Estebal, Geraldine A. Tongco, Gerino P. Mappatao \\ Department of Electronics and Communications Engineering, De La Salle University, Manila, Philippines
}

\begin{tabular}{l} 
Article Info \\
\hline Article history: \\
Received Aug 5, 2019 \\
Revised Oct 9, 2019 \\
Accepted Dec 11, 2019 \\
\hline Keywords: \\
Antenna polarization \\
Channel modelling \\
FM broadcast \\
Path loss \\
Path loss model
\end{tabular}

Corresponding Author:

Gerino P. Mappatao,

Department of Electronics and Communications Engineering,

De La Salle University,

2401 Taft Avenue, Malate, 0922 Manila, Philippines.

Email: gerino.mappatao@dlsu.edu.ph

\begin{abstract}
This paper proposes for the development of a path-loss model to improve the accuracy in predicting the signal level in office locations for the reception of FM broadcast. Identifying the factors that affect the signal level and eventually developing a model to predict the signal inside buildings will guide engineers in designing a broadcast system. A properly designed broadcast system will ensure optimum signal penetration in these listening areas. Further, the developed model can find applications in policy-making on the regulation of FM broadcast stations, both for analog and digital radio systems. Signal level measurements from three FM broadcast stations have been made inside eight office rooms in De La Salle University-Manila. With the three stations utilizing circularly polarized transmitting antennas, the measurements aim to determine the signal levels of the horizontal and vertical components of the received signal. These measured levels are used to determine the effects on the magnitude of the received signal of some factors, such as signal frequency and polarization, receiving antenna height, walls, transmitter-receiver distance, etc. Since the developed model is based on the measured signal levels in the actual office environment, its accuracy is then better than any of the existing models earlier developed.
\end{abstract}

This is an open access article under the CC BY-SA license.

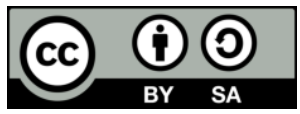

\section{INTRODUCTION}

The signal quality in any wireless communication system has the tendency to experience degradation due to several factors as the signal is propagated in the channel. The signal level decreases when the signal experiences different kinds of losses as it travels through a medium such as free space [1]. The signal level also experiences scattering, reflection and diffraction due to objects in the environment [2]. All these effects result to problematic signal reception in receivers affecting the quality of the demodulated information. Poor quality of demodulated signals results to monaural and hissing sound in FM receivers. This condition of receiving poor information quality is experienced in the office environment, where a bigger chunk of FM radio listeners is located. A better understanding of the behaviour of the signal in the listening area is therefore necessary to address the problem. This paper aims to characterize the FM broadcast channel in office locations to widen the comprehension on the dynamics of the FM signal in the room and eventually develop a path-loss model for office locations. With the onset of digital radio broadcasting in the Philippines, the results of this study will be very helpful in crafting new guidelines and policies on the regulation and operation of this new broadcast system. 
FM broadcast service in the Philippines operate in Band II (88-108 MHz) and uses an antenna system that is basially horizontally polarized (H-pol) $[3,4]$. However, the National Telecommunications Commission of the country allowed the use of circularly polarized (C-pol) antenna systems having a vertically polarized ( $\mathrm{V}$-pol) component that is no greater than the H-pol [5,6]. According to the National Association of Broadcasters (NAB) of the United States, the inclusion of the V-pol component is to improve the penetrating ability of the antenna system, especially in rugged terrains. Further, the NAB has specific values for the required signal strength an FM station has to produce within its principal community (usually in an urban setting) and another signal strength specification in the station's primary service area. Also, the NAB has specified the maximum usable signal strength within these areas. These signal specifications provide a dynamic range of signal levels i.e. to avoid excessive radiation that cause adverse effects [7-11], but strong enough to provide good signal reception [12]. These signal strength specifications, however, are the signals outside and not inside the buildings. A knowledge of the amount of signal inside the listening areas and the amount of signal attenuation will help in determining the ample signal needed for building penetration. This study is just limited to the measurement of the signal inside identified offices in the locale as indicated by a spectrum analyser. The measured signal is perceived to be the signal level including noise and distortion, at a particular frequency under consideration. The main objective of this study is to determine the factors that have effects on the signal level inside the buildings and to develop a model to predict the signal level more accurately based on these factors. Since the proposed model was developed based on the actual measured values in the actual listening environment, its accuracy in predicting the path loss and the signl level in this specific environment is better than any of the existing models that will be shown and discussed.

\section{RESEARCH METHOD}

As shown in Figure 1, the method adopted in this study starts from the measurements of the signal levels outside and inside several offices in a university. The signals emanate from three FM stations with Metro Manila as their primary service area. The data measured outside the building are used as the reference in calculating the loss (attenuation) that a signal underwent as it penetrates the building. The aim of the measurements done inside the rooms is to gather as many signal levels as can be in different locations, times (periods) of the day, signal frequencies and polarizations. The data analysis basically aims to determine the factors or parameters that may have effects on the signal level in the test locations. Based on these identified factors, a path loss model was developed. Model development involves the determination of the weigth of each of the identified factors and eventually leading to a path loss model for this specific listening environment.

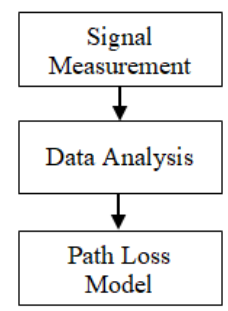

Figure 1. Simplified methodology adopted in the study

Throughout the measurements, the Advantest R3113 Series Spectrum Analyzer was used to measure the signal level from three FM broadcast transmitters utilizing a folded dipole receiving antenna that was constructed and patterned after the Ramsey Electronics Model TM100. It uses a ladder-line twin lead antenna cable and RG174U thin lead coaxial cable. The broadcast stations are in one common tower, all utilizing C-pol antenna systems. These stations operate at 89.9 MHz, 94.7 MHz and 103.5 MHz carrier frequencies and are about $6.3 \mathrm{~km}$ away from where the measurements were conducted. The eight office rooms considered in the study are typical office rooms with concrete walls, dimensions ( $\mathrm{W} \times \mathrm{L} \times \mathrm{H}$ ) ranging from $5 \mathrm{~m} \times 5 \mathrm{~m} \times 3 \mathrm{~m}$ to $15 \mathrm{~m} \times 11 \mathrm{~m} \times 4 \mathrm{~m}$. These rooms are all located within the campus of De La Salle University (DLSU) in Malate, Manila. Figure 2 illustrates one of the rooms used in the study and showing the locations of the test points. In the measurements, the receiving antenna is oriented towards the direction of the transmitter location at about 80 degrees northeast of DLSU. In each room, there are 540 measurements done, corresponding to five locations in a room (four corners and center of the room), three vertical locations (center, floor, ceiling), two polarizations (H-pol and V-pol), three frequencies (89.9 MHz, $94.7 \mathrm{MHz}$, 
and 103.5 MHz) and three times a day (morning, afternoon, evening). The data gathering was conducted twice in eight offices. The total measurements made in all eight rooms is 4320 all in a clear day.

In this paper, the reference signal is taken from the roof deck of the Henry Sy Sr. Hall (HSSH), approximately 50 meters high. From this location, a clear line-of-site is established and considered to be the signal level from outside of each room. From the gathered data, four forms of analyses are presented. These are polarization, signal level, statistical, and path loss model analyses. The path loss model analysis is presented using the five of the more popular path loss models, namely: Free Space Path Loss Model, Hata-Okumura Path Loss Model, Walfisch-Ikegami Path Loss Model, Clutter Factor Path Loss Model and the Hata-Okumura Extended Path Loss Model. Characterization of radio channels can be done with a certain accuracy by measuring the important parameters and developing the right mathematical models. Having these, engineers can predict signal coverage, achieve the required data rates, and attain specific performance attributes of alternative signaling and reception schemes [13-17].

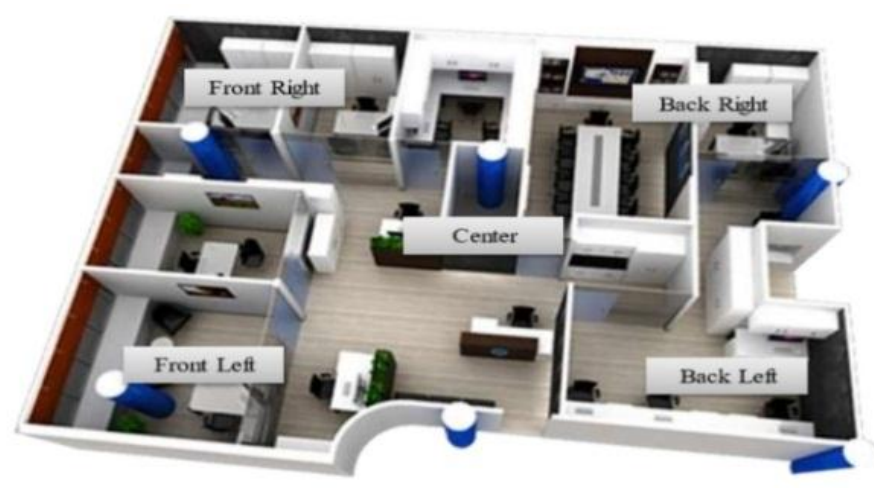

Figure 2. Test locations in an office room

The free-space path loss model is a basic radio propagation model for predicting the path loss of radio signals when it travels from the transmitter to the receiver. It is the attenuation of an electromagnetic wave that would produce a line-of-sight path that would not pass any obstructions that cause reflection or diffraction. This model assumes ideal atmospheric conditions. It is dependent on the distance of the transmitter to receiver and frequency. The equation of free-space path loss is:

$$
P L=32.45+20 \log (d)+20 \log (f)
$$

where $d$ is the distance in kilometers and $f$ is the frequency in $\mathrm{MHz}$.

The Hata-Okumura (or simply Hata) path loss model is an empirical formula combining the effects of free space path loss, terrain induced path loss, and extensive measurements or radio propagation losses. This model is widely used in the industry. It only requires four parameters and the path loss equation of the Hata model is $[18,19]$.

$$
\begin{aligned}
& P L=69.55+26.16 \log (f)-13.82 \log 2(h b)-C+(44.9-6.55 \operatorname{Loghb}) \log d \\
& \text { Where } \quad C=8.29(\log 1.54 h m)^{2}-1.1
\end{aligned}
$$

$d$ is the distance in kilometers, $f$ is the frequency in $\mathrm{MHz}, h m$ is the receiver antenna height in meters, $h b$ is the transmitter antenna height in meters.

The Walfisch-Ikegami path loss model is the combination of the Walfisch-Bertoni model and the Ikegami model. It is considered as the limiting case of flat edge model when the number of buildings is enough for the field to settle [20,21]. It is created with respect to the scattering and reflection above and between buildings. The equation of Walfisch-Ikegami path loss model is:

$$
P L=42.64+26 \log d+20 \log f
$$

where $d$ is the distance in kilometers, $f$ is the frequency in MHz.

The clutter factor path loss model combines the plane earth loss model with an extra loss parameter. This model introduces frequency to the plane earth loss. It is based on the Egli model with an equation of [19]:

$$
P L=40 \log (d)+20 \log (f)+20 \log (h b)+L m
$$


where $\quad L m=76.3-10 \log (\mathrm{hm})$ for $\mathrm{hm}<10 \mathrm{~m}$

$\mathrm{Lm}=76.3-20 \log (\mathrm{hm})$ for $\mathrm{hm} \geq 10 \mathrm{~m}$

$d$ is the distance in kilometres, $f$ is the frequency in $\mathrm{MHz}, h m$ is the receiver antenna height in meters and $h b$ is the transmitter antenna height in meters.

Lastly, the Hata-Okumura extended path loss model is an improvement to the most used empirical propagation model. The International Telecommunication Union (ITU) did the improvement. It is also referred to as the Electronic Communication Committee (ECC) - 33 model. The equation for this extended model [19] is:

$$
P L=A_{f s}+A_{b m}-G_{t}-G_{r}
$$

where $A_{f s}$ is free space attenuation, $A_{b m}$ is basic median path loss, $G_{t}$ is the transmitter height gain factor and $G_{r}$ is received antenna height gain factor. They are individually defined as

$$
\begin{aligned}
A_{f s} & =92.4+20 \log (d)+20 \log (f) \\
A_{b m} & =20.41+9.83 \log (d)+7.89 \log (f)+9.56(\log (f))^{2} \\
G_{t} & =\log \left(\frac{h b}{200}\right)\left[13.958+5.8(\log (d))^{2}\right] \\
G_{r} & =[42.57+13.7 \log (f)][\log h m-0.585]
\end{aligned}
$$

where $d$ is the distance in kilometres, $f$ is the frequency in $\mathrm{GHz}, h m$ is the receiver antenna height in meters and $h b$ is the transmitter antenna height in meters.

\section{RESULTS AND ANALYSIS}

There are 30 measured values for each station from the roof deck of HSSH, 15 each polarization. The measurements were done from 9:30 in the morning to 4:30 in the afternoon. Table 1 shows the average of these measured values. These are the values considered to be the reference in the analysis of all measured values in the office rooms. From the values, the antenna system of $89.9 \mathrm{MHz}$ station has the $\mathrm{V}$-pol almost the same as the H-pol (50-50 ratio). However, the antenna systems of the $94.7 \mathrm{MHz}$ and $103.5 \mathrm{MHz}$ stations have a V-pol that is greater than the $\mathrm{H}$-pol. The eight rooms where the measurements are done are in four buildings within the university. The rooms are in the ground, second, third, fifth, 14th and 20th floors of these buildings. The signals measured in the rooms went through a minimum of one wall and a maximum of four walls from the transmitter.

Table 1. Average line-of-sight signal levels

\begin{tabular}{ccc}
\hline $\begin{array}{c}\text { Frequency } \\
(\mathrm{MHz})\end{array}$ & $\begin{array}{c}\text { H-pol } \\
(\mathrm{dBm})\end{array}$ & $\begin{array}{c}\text { V-pol } \\
(\mathrm{dBm})\end{array}$ \\
\hline 89.9 & -43.83 & -44.04 \\
94.7 & -42.09 & -41.00 \\
103.5 & -47.90 & -46.62 \\
\hline
\end{tabular}

A total of 4320 data samples were collected from the data gathering portion of this study. Using the the large population of measured samples (4320 in all), data analysis is done four ways as described earlier. The purpose of these analyses is to determine the factors that have significant effect on the signal level inside the rooms being considered.

\subsection{Polarization analysis}

This analysis determines the effect of polarization on the signal level inside the rooms. The average of the V-pol and H-pol data gathered from the measurements in all eight offices was obtained. Each office has three values for the horizontal polarization and another three for the vertical polarization. One value corresponds to the average of the signal strength in different antenna heights, room positions, and testing time for one frequency. Table 2 shows the average $\mathrm{V}$-pol and $\mathrm{H}$-pol measured signal level in the offices. Relatively, the value of the H-pol signal is greater than the V-pol value, so basically, the radiators are really H-pol radiators.

Table 2. Average signal levels in the offices

\begin{tabular}{ccc}
\hline Frequency $(\mathrm{MHz})$ & $\mathrm{H}-$ pol $(\mathrm{dBm})$ & V-pol $(\mathrm{dBm})$ \\
\hline 89.9 & -72.80 & -72.86 \\
94.7 & -71.69 & -71.77 \\
103.5 & -72.59 & -73.15 \\
\hline
\end{tabular}


Table 3 is provided to better appreciate the values and easily compare the two components with reference to the outdoor values shown in Table 2. The table shows the average attenuation done to the signal at the three frequencies. The average value is determined by subtracting the values in Table 2 from the outdoor values. It is observed that the $\mathrm{H}$-pol and $\mathrm{V}$-pol ratios for $89.9 \mathrm{MHz}$ are slightly close. However, for $94.7 \mathrm{MHz}$, the $\mathrm{V}$-pol is attenuated more than the $\mathrm{H}$-pol. Finally, at $103.5 \mathrm{MHz}$, the attenuation encountered by the V-pol has increased compared to its value in $94.7 \mathrm{MHz}$. However minimal and can be tolerated, there is a trend that as the frequency increases, the $\mathrm{V}$-pol component encounters higher attenuation than its H-pol counterpart.

Table 3. Average attenuation encountered by the signal levels entering the offices

\begin{tabular}{cccc}
\hline Frequency $(\mathrm{MHz})$ & H-pol $(\mathrm{dB})$ & V-pol $(\mathrm{dB})$ & Difference $(\mathrm{dB})$ \\
\hline 89.9 & 28.97 & 28.82 & -0.15 \\
94.7 & 29.60 & 30.77 & 1.17 \\
103.5 & 24.70 & 26.53 & 1.83 \\
\hline
\end{tabular}

\subsection{Statistical analysis}

This analysis determines any correlation between the signal frequency and polarization, time of measurement, and the receiving antenna height inside an office. The analysis is needed primarily to determine if there is any relationship existing among the parameters. The "corrcoef" function of Matlab is used to generate the correlation coefficient matrix of the dataset of parameters. The dataset for each parameter is taken from the 4320 measured values that were classified according to parameter. The correlation coefficient matrix returns an $\mathrm{n} x \mathrm{n}$ matrix of the ' $\mathrm{r}$ ' value of the parameters.

The ' $r$ ' value is the Pearson's ' $r$ ' correlation coefficient which determines the strength of the parameters. If the ' $r$ ' coefficient is $+0.70-+1$, it denotes a very strong to perfect positive relationship. As the value goes closer to zero, the strength of the relationship weakens. If the ' $r$ ' coefficient is $0.3-0$, there is no relationship among the parameters [22]. The ' $r$ ' value may also determine an anti-correlation or a strong negative linear relationship. This occurs when the ' $r$ ' coefficient is -0.70 to -1 .

In this study, correlation of the frequency, polarization $\left(\mathrm{P}_{\mathrm{H}}\right.$ and $\left.\mathrm{P}_{\mathrm{V}}\right)$, time, and receiver height are determined in the test locations. The correlation coefficient matrix generated is therefore a $5 \times 5$ matrix. All the ' $r$ ' values generated in the coefficient matrices are close to zero as shown in Table 4. Based on this, the parameters do not have any relationship with each other. Also, time of signal measurement and polarization have negligible effect on the signal level inside the rooms and therefore do not appear in the proposed model. Thus, it can be said that there are other factors that have a greater effect on the signal as it enters an office room.

Table 4. Correlation coefficient " $r$ "

\begin{tabular}{lccccc}
\multicolumn{7}{c}{ Table 4. Correlation coefficient " $\mathrm{r}$ " } \\
\hline $\mathrm{P}_{\mathrm{H}}$ & $\mathrm{P}_{\mathrm{V}}$ & Time & Height & Frequency \\
$\mathrm{P}_{\mathrm{V}}$ & 1.0000 & 0.8445 & -0.0924 & 0.0643 & -0.0010 \\
Time & 0.8445 & 1.0000 & -0.0918 & 0.0779 & 0.0297 \\
Height & -0.0924 & -0.0918 & 1.0000 & -0.8155 & 0.0014 \\
Frequency & -0.0643 & 0.0779 & -0.8155 & 1.0000 & -0.0021 \\
\hline
\end{tabular}

\subsection{Signal level analysis}

This analysis aims to determine the effect of the transmitter-receiver distance, antenna height, frequency and the number of walls that the signal went through from the transmitter. The five test points in a room are converted into their respective distances from the transmitter. These distances represent the offices. Each room position, the average signals for each receiving antenna height are graphed against each other. Thus, three lines per graph can be shown. This is done for each frequency, time and polarization. Hence, there are 90 plots describing the signal level in the various offices. Plotting the signals in this manner will help determine if there is a trend in the signals received in a specific position inside an office. The $\mathrm{x}$-axis of the plot is the distance in kilometers of each office with respect to the transmitter. The $y$-axis is the average of the received power in $-\mathrm{dBm}$.

Evident in the 90 plots is a common shape or line. All plots have the same trend with only the range of average signals changing by a few $\mathrm{dBm}$. Figure 3 shows a sample of the signal level plotted with the distance. Because the plots of the average signal revealed a trend, the transmitter-receiver distance has an affect on the signal level. The office room located at the highest elevation (14th floor of HSSH) registers the highest signal level. The frequency of the received signal also influences the measured signal level. This was 
confirmed by determining the losses encountered by the signals at different frequencies at common test points in the different rooms.

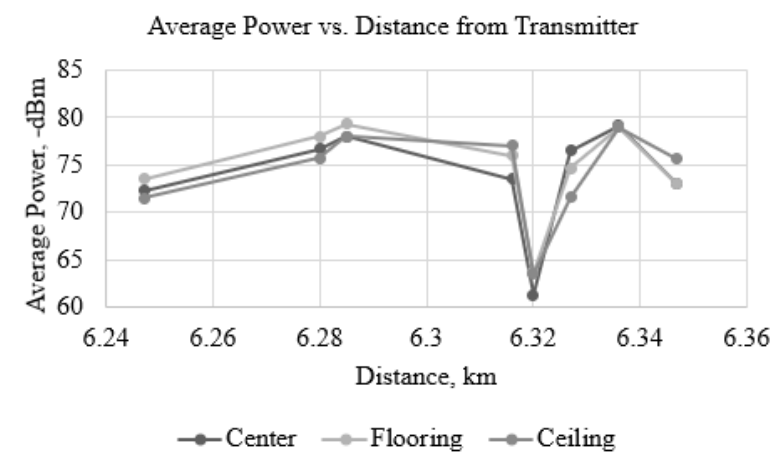

Figure 3. Plot of the signal levels over the distance. Data come from the measured values of the H-pol component at the center portion of the rooms

In this study, the number of walls that the signal went through from the transmitter to the test location is determined by counting the number of walls the signal passed through if it is projected straight from the transmitter to the test location. The attenuation done on the signal by the number of walls on the signal level is determined by analyzing the measured signals that went through different wall penetrations. As expected, the number of walls a signal is passing through has a significant effect on the received signal level.

\subsection{Path loss models analysis}

In this data analysis, five path-loss models are considered. The calculated path loss is converted to received power to show the differences in the received signal level of each model considered. The measured signal levels are varying from $-60 \mathrm{dBm}$ to $-80 \mathrm{dBm}$. All five conventional methods of determining the path loss have inaccuracies compared to the measured values. Of these five models, the best is the Hata-Okumura extended model whose signal level ranges from $-35 \mathrm{dBm}$ to $80 \mathrm{dBm}$. However, it shows a huge error if the receiver antenna height is less than $10 \mathrm{~m}$ and the error gets bigger as the receiver approaches the ground level. The four remaining models produce values that are far from the measured signal level values and therefore produce great errors.

Since even the best path-loss model has limitations, the authors developed a simple model to improve the accuracy in predicting the signal in the office rooms using the data gathered. Based on the foregoing analyses, the study identified four factors that have direct effect on the signal level inside the rooms: receiving antenna height, signal frequency, transmitter-receiver distance and the number of walls that the signal is going through. The model is, therefore, in terms of these factors. To create the appropriate model, the least squares fitting approach was used. A linear regression framework was followed to fit the data into a least squares model. The data are first arranged according to the parameters mentioned above and then imported into Matlab. The "fitlm" function is then used to create the initial least squares model of the data. Residuals are then observed and removed to improve the accuracy of the model. After this, the model is further improved using the "step" function. Parameters are added or removed from the model to improve its effectiveness. When the appropriate model is created, the coefficients are then obtained to finalize the model. The final model obtained is:

$$
P \mathrm{~L}=32.3069+(-0.0565 \times h)+(4.8869 \times d)+(0.0185 \times f)+(3.5571 \times w)
$$

Where $f$ is the frequency in $\mathrm{MHz}, d$ is the transmitter-receiver distance in kilometres, $h$ is the receiver antenna height in meters and $w$ is the number of walls. In this model, an attenuation of more than $3.5 \mathrm{~dB}$ is introduced by each wall that the signal is penetrating. To show the accuracy of the proposed model, Figure 4 is provided showing a plot of the calculated signal levels using the developed model and the conventional models as compared with the measured values. The figure was produced with the distance being varied while the other parameters $(h, f$ and $w)$ are held constant. As shown, the developed model consistently approximates closely the measured values. Although ECC - 33 model gives a good approximation but not quite compared to the developed model. It is also evident in the figure that the least accurate are the Freespace and Clutter Factor path-loss models. The just described model gives a very good approximation on the signal path loss inside buildings at FM broadcast frequencies. It can also be used, with lesser accuracy, to other systems such as the ones described in [23-25]. 


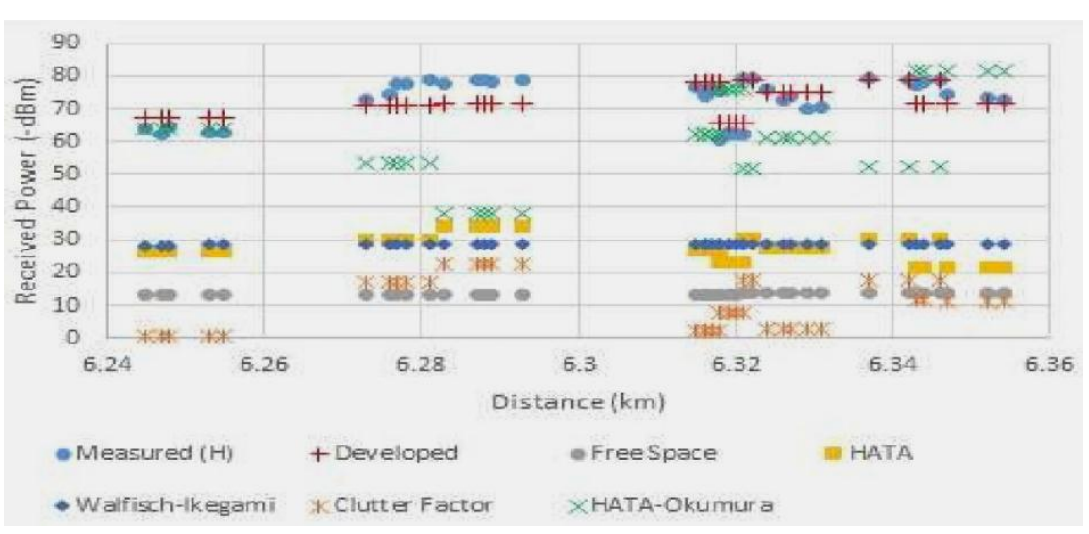

Figure 4. Received signal level for as determined by the different models at $89.9 \mathrm{MHz}$ as compared with the measured values

\section{CONCLUSION}

The measured received signal levels obtained from the actual experimentation were analyzed. With the volume of measured data gathered in this study, a suitable model for signal level prediction inside an office environment was developed. Being developed using the actual received data in the office transmitted by FM transmitters, the model is the best-fit model in predicting the signal level in office environments for FM broadcast. The model serves as an important source of information in determining the minimum required power an FM station must transmit to better serve its service area. It can also help antenna engineers in the design of antenna systems with the proper radiation characteristics requiring lower transmitter power but providing the required signal level. For future directives, a more comprehensive study is recommended to further improve the accuracy of the model. One is to do more tests on the observed increased attenuation on the V-pol signal component more than the H-pol component as the frequency is increased. Another is the incorporaton of multipath fading in the model.

\section{ACKNOWLEDGEMENTS}

The author would like to thank the University Research Coordination Office of DLSU and the DLSU Science foundation for the realization of this paper.

\section{REFERENCES}

[1] N. Masadan, et al., "Long range channel characteristics through foliage," Bulletin of Electrical Engineering and Informatics, vol. 8, no. 3, pp. 941-950, 2019.

[2] A. Budalal, et al., "The effects of rain fade on millimetre wave channel in tropical climate," Bulletin of Electrical Engineering and Informatics, vol. 8, no. 2, pp. 653-664, 2019.

[3] G. Mappatao, "The compliance to broadcast standards of a side-mounted circularly polarized antenna," International Journal on Communications Antenna and Propagation, vol. 8, no. 3, pp. 240-247, 2018.

[4] G. P. Mappatao, "Compliance to broadcast standards of patented broadcast antennas: The circularly polarized Antenna," International Journal on Communications Antenna and Propagation, vol. 7, no. 2, pp. 154-161, 2017.

[5] G. Mappatao, "Radiation characteristics of patterns derived from shunt-fed slanted dipole linear arrays," International Journal on Communications Antenna and Propagation, vol. 6, no. 3, pp. 138-145, 2016.

[6] G. Mappatao, "Reducing FM broadcast energy consumption using directional radiation pattern," ARPN Journal of Engineering and Applied Sciences, vol. 10, no. 15, pp. 6484-6490, 2015.

[7] A. Mumin, "Assessment of Electromagnetic Absorption towards Human Head Using Specific Absorption Rate," Bulletin of Electrical Engineering and Informatics, vol. 7, no. 4, pp. 657-664, 2018.

[8] F. Caluyo and G. Mappatao, "Azimuth radiation pattern shaping and control for FM broadcast," International Journal on Communications Antenna and Propagation, vol. 1, no. 3, pp. 284-289, 2011.

[9] I. Fayed, "Electromagnetic Radiation and its effects on human beings: Survey and Environmental Recommendations," in 15th Sci. Symp. Hajj, Umr. Madinah, pp. 35-47, 2015.

[10] M. Kuzairi, et al., "Radio frequency radiation measurement for base tower station safety compliances: a case study in Pulau Pinang Malaysia," Bulletin of Electrical Engineering and Informatics, vol. 8, no. 1, pp. 150-157, 2019.

[11] G. Mappatao, "Reducing the downward radiation of slanted dipole array," in ISIEA 2010 - 2010 IEEE Symposium on Industrial Electronics and Applications, pp. 290-294, 2010.

[12] G. Mappatao, "Radiation pattern shaping for FM broadcast-optimizing coverage," ISIEA 2010 - 2010 IEEE Symposium on Industrial Electronics and Applications, pp. 222-225, 2010. 
[13] A. Kalachikov and N. Shelkunov, "Performance Evaluation of the Detection Algorithms for MIMO Spatial Multiplexing Based on Analytical Wireless MIMO Channel Models," in 2018 XIV International ScientificTechnical Conference on Actual Problems of Electronics Instrument Engineering (APEIE), pp. 180-183, 2018.

[14] C. Perez-Vega and J. M. Zamanillo, "Path-loss model for broadcasting applications and outdoor communication systems in the VHF and UHF bands," IEEE Transactions on Broadcasting, vol. 48, no. 2, pp. 91-96, 2002.

[15] F. Caluyo and G. Mappatao, "Optimizing FM broadcast coverage using hybrid optimizations," International Journal on Communications Antenna and Propagation, vol. 1, no. 5, pp. 439-445, 2011.

[16] A. Alexander, A. Kalachikov and N. S. Shelkunov, "Construction and Validation of Analytical Wireless MIMO Channel Models Based on Channel Measurement Data," in 2018 XIV International Scientific-Technical Conference on Actual Problems of Electronics Instrument Engineering (APEIE), pp. 175-179, 2018.

[17] V. Anusha, G. K. Nithya GK and S. N. Rao, "A comprehensive survey of electromagnetic propagation models," in 2017 International Conference on Communication and Signal Processing (ICCSP), pp. 1457-1462, 2017.

[18] M. E. Anggraeni and N. Dwiyanti, "Performance Analysis of Empirical Path Loss Models for UHF TV Broadcast on Mountainous Area," in 2018 International Electronics Symposium on Engineering Technology and Applications (IES-ETA), pp. 247-252, 2018.

[19] P. Pathania, P. Kumar and S. B. Rana, "Performance evaluation of path loss parameters for broadcasting applications," International Journal of Research in Engineering and Technology, vol. 3, no. 4, pp. 520-528, 2014.

[20] A. Tahat and M. Taha, "Statistical tuning of Walfisch-lkegami propagation model using Particle Swarm Optimization," in 19th IEEE Symposium on Communications and Vehicular Technology in the Benelux (SCVT), pp. 1-6, 2012

[21] S. Phaiboon and P. Phokharatkul, "Comparison between Xia and Walfisch-Ikegami models for low-rise building path loss prediction," in 2010 IEEE Region 10 Conference, pp. 889-892, 2010.

[22] S. Sabilla, et al., "Optimizing Threshold Using Pearson Correlation for Selecting Features of Electronic Noise Signals,” International Journal of Intelligent Engineering \& Systems, vol. 12, no. 6, pp. 81-90, 2019.

[23] I. M. Bautista, M. K. Orsos, M. A. Ribo, J. C. Castillo, G. Mappatao, "Development of a remote tending system for analog broadcast transmitters," Indonesian Journal of Electrical Engineering and Computer Science, vol. 15, no. 3, pp. 1474-1484, 2019.

[24] C. Aragones, P. Elpa, D. Pangan, Q. Santos, G. Mappatao, "Scalable remote water monitoring system using radio frequency links," Lecture Notes in Electrical Engineering, vol. 379, pp. 13-23, 2016.

[25] I. Bautista, M. Orsos, M. Ribo, J. C. Castillo, G. Mappatao, "Remote Tending of Modern Broadcast Transmitters," Indonesian Journal of Electrical Engineering and Computer Science, vol. 15, no. 3, pp. 1491-1500, 2019.

\section{BIOGRAPHIES OF AUTHORS}

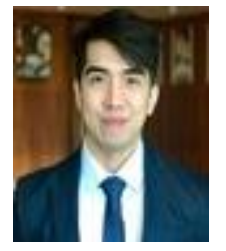

Marco G. Domingo was born in Davao, Philippines in 1993. He received the B.S. degree in electronics and communications engineering (ECE) from De La Salle University-Manila, Philippines in 2014. He studied MSc in Automotive Electronic Engineering at the University of Brighton, United Kingdom. He is currently a Developing Engineer at Tata Technologies.

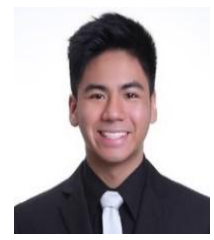

Prince Kendrick Estebal was born in Laguna, Philippines in 1994. He received the B.S. degree in electronics and communications engineering (ECE) from De La Salle University (DLSU)Manila, Philippines in 2014. He has been an active member of the Electronics and Communications Engineering Society of DLSU. He is also a member of Institute of Electronics and Communications Engineers of the Philippines (IECEP) and Institute of Electrical and Electronics Engineers (IEEE).

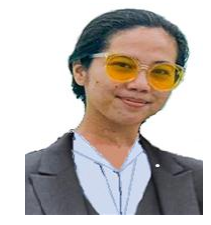

Geraldine A. Tongco was born in Mandaluyong, Philippines in 1993. He received the B.S. degree in electronics and communications engineering (ECE) from De La Salle UniversityManila, Philippines in 2014. She has been an active member of the Electronics and Communications Engineering Society of DLSU.

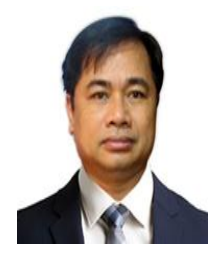

Gerino P. Mappatao was born in Tuao, Cagayan, Philippines. He received the B.S. degree in electronics and communications engineering (ECE) from Saint Louis University, Baguio City, Philippines in 1989, the M.S. and PhD degrees in ECE from De La Salle University-Manila, Philippines in 1998 and 2012, respectively. He is currently an Associate Professor of Electronics and Communications Engineering at De La Salle University-Manila. He authored and coauthored papers in conference proceedings and journals on antennas, broadcast engineering, wireless communications and image processing. 